\title{
Commentary
}

\section{Biological risk assessment: A challenge for occupational safety and health practitioners during the COVID-19 (SARS-CoV-2) pandemic}

\author{
Carlos Carvalhais $^{\mathrm{a}, \mathrm{b}, \mathrm{c}, *}$, Micaela Querido ${ }^{\mathrm{b}, \mathrm{c}, \mathrm{d}, \mathrm{e}}$, Cristiana, C. Pereira $^{\mathrm{b}, \mathrm{c}, \mathrm{d}}$ and Joana Santos ${ }^{\mathrm{a}, \mathrm{f}, \mathrm{g}}$ \\ ${ }^{a}$ Environmental Health Scientific Area, Health and Environment Research Center (CISA), School of Health of \\ Polytechnic Institute of Porto (ESSIP.Porto), Rua Dr. António Bernardino de Almeida, Porto, Portugal \\ ${ }^{\mathrm{b}}$ Epidemiology Research Unit (EPIUnit), Institute of Public Health, University of Porto, Rua das Taipas, Porto, \\ Portugal \\ ${ }^{\mathrm{c}}$ Laboratory for Integrative and Translational Research in Population Health (ITR), Rua das Taipas, Porto, \\ Portugal \\ ${ }^{\mathrm{d}}$ Environmental Health department, National Institute of Health Dr Ricardo Jorge (INSA), Rua Alexandre \\ Herculano, Porto, Portugal \\ e Instituto de Ciências Biomédicas Abel Salazar (ICBAS), Universidade do Porto, Rua de Jorge Viterbo Ferreira \\ Porto, Portugal \\ ${ }^{\mathrm{f}}$ Center for Rehabilitation Research (CIR), School of Health of Polytechnic Institute of Porto (ESS|P.Porto), Rua \\ Dr. António Bernardino de Almeida, Porto, Portugal

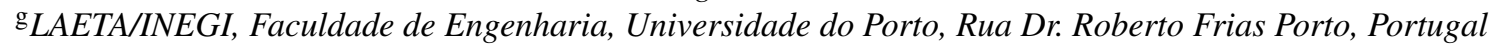

Received 11 December 2020

Accepted 4 January 2021

\begin{abstract}
.
BACKGROUND: The COVID-19 global pandemic brought several challenges to occupational safety and health practice. One of these is the need to (re)assess the occupational risks, particularly, biological risks.

OBJECTIVE: The purpose of this work is to promote guidance to occupational safety and health practitioners when conducting a biological risk assessment in this context.

METHODS: The main steps of the biological risk assessment are explained with some inputs regarding the novelty posed by SARS-CoV-2 and an example of a qualitative risk assessment method is presented. Also, its application to two different activities was exemplified.

RESULTS: In both cases, the assessment considered that vulnerable workers were working from home or in medical leave. The results showed low or medium risk level for the assessed tasks. For medium risk level, additional controls are advised, such maintain social distancing, sanitize instruments/equipment before use, use proper and well-maintained PPE (when applicable), and promote awareness sessions to spread good practices at work. Employers must be aware of their obligations regarding biological risk assessment and OSH practitioners must be prepared to screen and link the abundance of scientific evidence generated following the outbreak, with the technical practice.
\end{abstract}

*Address for correspondence: Carlos Carvalhais, Rua Dr. António Bernardino de Almeida, 400, 4200-072 Porto, Portugal.
Tel./Fax: +3512220610 00; Fax: +3512220610 01; E-mail: caa@ess.ipp.pt. 
CONCLUSIONS: This paper could be an important contribution to OSH practice since it highlights the need to (re)assess occupational risks, especially biological risk, to ensure a safe return to work, providing technical guidance.

Keywords: Biological risk, COVID-19, risk assessment, OSH practice

\section{Introduction}

COVID-19, caused by the novel coronavirus termed severe acute respiratory syndrome coronavirus 2 (SARS-CoV-2), originated in Wuhan/China in December 2019 [1]. Subsequently, COVID-19 spread over the whole world and was labelled a pandemic by the World Health Organization (WHO) on March 11, 2020 [2].

During an infectious disease outbreak like COVID19, large companies around the world have a major part to play, especially in terms of preparedness and emergency response. In face of such a scenario, companies must consider both their national governments' health contingency plans, and WHO and International Labour Organization's (ILO) recommendations, to achieve a desirable balance between the needed reopening and the maintenance of limited infection rates, which relies greatly in workers' awareness and health protection.

Occupational safety and health $(\mathrm{OSH})$ practitioners play a major role in planning for ensuring safe working conditions and for when cases of infected workers occur in the company. They must advise and technically assist the companies, workers, and their representatives, on aspects related to the interrelation between health and work. There are two areas in which their activity is specifically focused: the identification and assessment of occupational risks (those risks derived from work) and, on the other hand, the assessment of people's health status. In both cases the result is the development and implementation of recommendations that allow adjusting the binomial health and work with benefit for all. Employers must revise their risk assessment when there is a change in the work process and to consider all risks involved: biological, psychosocial, ergonomic, chemical, physical, among others. Risk assessment is about identifying hazards and thinking of what might cause harm to people while deciding on taking reasonable steps to reduce the involved risk. Currently, most risk assessments are based on workplace, work characteristics and work factors. The most usual methodology to conduct a risk assessment is a five-step process comprising: a) to identify the hazards, b) to identify who might be harmed and how, c) to evaluate the risks - Identifying and deciding on OSH risk control measures, d) to record who is responsible for implementing which control measure and the adequate timeframe, and e) to record and monitor the findings, and review the risk assessment when necessary [3].

This new coronavirus paradigm brings the need to protect vulnerable workers against occupational risks and specifically to biological risks. Biological risk assessment requires knowing personal information from workers, their health susceptibilities, and biological state, to take into account for the evaluation of updated risks, and to draw prevention and protection measures which are necessary. Suddenly, sectors of activity where no biological risk was identified before, must adapt quickly and assess the risks in this new context: possible occupational exposure to SARS-CoV-2. It is known that biological agents have a ubiquitous presence in the environment, and the occupational settings where usually the exposure to biological agents occur are those where there is contact with animals, organic materials, food, waste, wastewater, blood or other body fluids, among others [4]. In this pandemic context, people with jobs that put them in physical contact with others are at the greatest risk of contracting COVID-19. Workers in the healthcare, residential and home care, and laboratories handling SARS-CoV-2 have increased risk of exposure, but, despite the novelty of coronavirus, biological risk was already a reality for them. Other workers more exposed include, for example, those involved in food supply and retail, waste collection, utilities, police and security, and public transport. In most workplaces, the risk of catching a general infection, such as a cold, a flu, is no higher than in any other public place and employers may not have to take any action [5]. However, in the actual context, it remains true that, in general, the risk of contracting COVID-19 is similar than in any other public place, but the sanitary or public health actions must be implemented and adapted to workplaces. In this sense and since the need to (re)assess occupational risks, particularly biological risk, is high, the aim of this work is to clarify and provide some guidance to OSH practitioners to conduct a biological risk assessment considering the actual pandemic context. Two cases are also presented to provide a practical application of the risk assessment method presented in this article. 


\section{Biological agents: SARS-CoV-2 classification}

The European Commission Directive 2000/54/EC defines biological agent as "microorganisms, including those which have been genetically modified, cell cultures and human endoparasites, which may be able to provoke any infection, allergy or toxicity", and classifies them into 4 risk groups according to their level of risk of infection, as follows (if the biological agent to be assessed cannot be classified clearly in one of the following groups, it shall be classified in the highest risk group among the alternatives) [6]:

- a "group 1 biological agent" means one that is unlikely to cause human disease to employees;

- a "group 2 biological agent" means one that can cause human disease and might be a hazard to employees, although it is unlikely to spread to the community and in respect of which there is usually effective prophylaxis or treatment available;

- a "group 3 biological agent" means one that can cause severe human disease and presents a serious hazard to employees and which may present a risk of spreading to the community, though there is usually effective prophylaxis or treatment available;

- a "group 4 biological agent" means one that causes severe human disease and is a serious hazard to employees and which may present a high risk of spreading to the community and in respect of which there is usually no effective prophylaxis or treatment available.

Countries such as Germany, Belgium, the United Kingdom and Canada have provisionally classified SARS-CoV-2 as a risk group 3 biological agent [7] which is in alignment with European Commission classification, which recently updated the EU Biological Agents directive, which lays down minimum requirements for the health and safety of workers exposed to biological agents at work. Several other EU members have started taking measures regarding the classification of SARS-CoV-2 in risk group 3 [8].

\section{Biological risk assessment: Usual steps with SARS-CoV-2 in mind}

In terms of occupational exposure to biological agents, two different situations are considered: their deliberate use (the company knows which biological agents their workers are exposed to) and a potential for exposure (when the biological agents may be present, introduced or grown during the processes). In general, the risk assessment consists of characterizing the risks, having a strategy for mitigating the risks, and providing an adequately trained workforce to safely perform the tasks. Risk assessment is carried out by firstly identifying the hazard and then following the transmission chain from the "reservoir" (of the biological hazard) to the worker, secondly identifying risk control measures following the hierarchy of control to reduce the exposure. The risk of exposure should be controlled as early as possible in the transmission chain. The risk assessment must consider how workers may be exposed to microorganisms (or to blood or bodily fluids, animals or animal products or waste materials which are known to potentially carry microorganisms). In general, unless it has been treated, employers should assume that human and animal waste materials, including sewage, may contain harmful microorganisms that could cause an infection. Once mitigation strategies are addressed, and the personnel properly trained, and the necessary equipment and work practices defined, the process is complete. A biological risk assessment usually involves the following steps.

\subsection{Identifying the biological agent hazards and the workers at higher risk}

In this step the use of checklists can be very useful. Generally, the information to collect can be divided in the following topics:

- Microbiological information (agent, agent classification, mode of transmission (epidemiological chain), vaccine availability (if applicable); If the use of biological agents is deliberate then information about the biological agent used should be included in the inventory/database of hazardous substances, which may include chemical and biological agents;

- Tasks, activities and spaces where the biological agent's presence is expected or foreseeable, and workers involved;

- Hazard assessment - identifying the potential for the occurrence of accidents (e.g. manipulation of sharp devices, container availability and capacity, availability of work instructions/procedures);

- Specific COVID-19 requirements - identifying the potential for contact with public and other workers; 


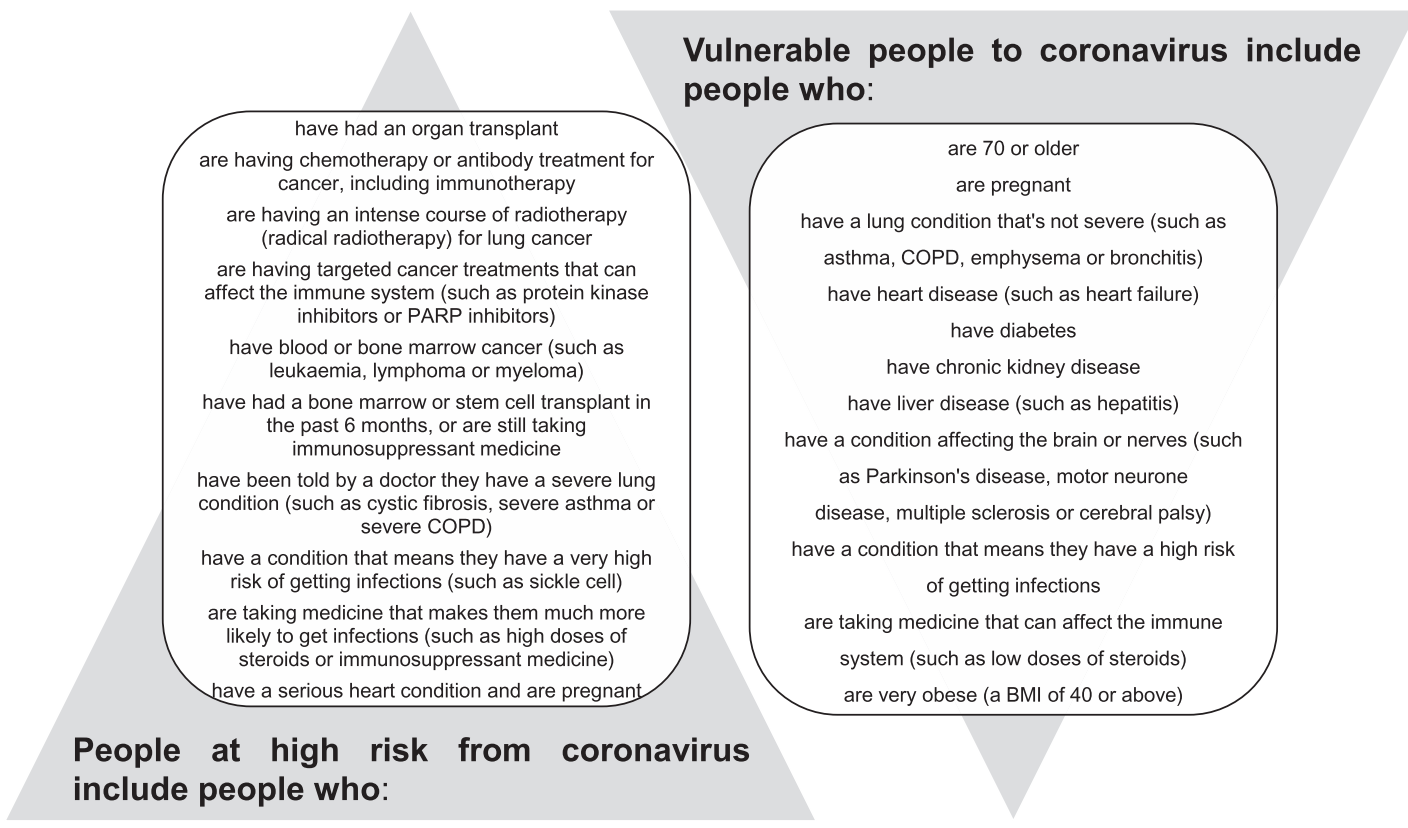

Fig. 1. Vulnerable and high-risk people to coronavirus (adapted from [9]).

- Infrastructural and machinery risks (handwashing sinks availability, ventilation system, building characteristics, autoclave, work instructions/ procedures, etc.);

- Human factors (Personal Protective Equipment (PPE) Requirements, experience and/or training requirements to manipulate the agent, etc.);

- Specific COVID-19 information: identifying high risk/vulnerable workers (Fig. 1); drawing a specific contingency plan; instructions to access the facilities; instructions to adapt work; instructions to canteens and common areas access; facilities' hygiene plan; good hygiene and conduct practices for workers.

\subsection{Evaluating and prioritizing the intervention in terms of importance}

In cases where the use of the biological agent is deliberate, a qualitive risk assessment matrix can be applied, to rank the risks based on their probability to cause harm and the consequences of the expected outcome.

There are several risks assessment tools made available by international agencies, such as, for example, the Online Interactive Risk assessment (OIRA) tool, provided by the European Agency for Safety and Health at Work (EU-OSHA) [10]. An example of a qualitative method to assess biological risks is
Table 1

Likelihood of biohazard occurrence

\begin{tabular}{ll}
\hline Hazard likelihood & Description of likelihood \\
\hline Rare & $\begin{array}{c}\text { Will only occur in } \\
\text { exceptional circumstances } \\
\text { Not likely to occur } \\
\text { within the foreseeable future } \\
\text { May occur within the } \\
\text { foreseeable future, sporadic } \\
\text { Possible }\end{array}$ \\
& $\begin{array}{l}\text { Likposure is possible } \\
\text { the foreseeable future, }\end{array}$ \\
Likely & routine exposure if likely \\
& Almost certain to occur \\
within the foreseeable future, \\
Highly likely
\end{tabular}

presented below. Tables 1, 2 and 3 should be used to assess the risk level associated with each identified biohazard per activity. Then, by comparing the obtained risk level with criteria presented in Table 4, it is possible to prioritize the intervention, if needed. In utilising a risk assessment matrix, $\mathrm{OSH}$ practitioners decide, in their expert view, the likelihood that a defined risk will occur, then cross reference this (in this matrix) with the worst-case consequence that may result. Where these values intersect on the coloured area of the matrix, is the assessed risk level.

Although a qualitative approach to combining likelihood and consequence variables in a risk matrix is provided as a risk evaluation method here, it is important to note that quantitative and semi-quantitative 
Table 2

Consequence of biohazard occurrence

\begin{tabular}{ll}
\hline Injury severity & Description of consequence \\
\hline Insignificant & No treatment required \\
Minor & Minor injury requiring first aid \\
Moderate & Injury requiring medical \\
& treatment or lost time \\
Major & Serious injury (injuries) \\
& requiring specialist medical \\
& treatment or hospitalization \\
Critical & Loss of life, permanent \\
& disability, or multiple \\
& serious injuries \\
\hline
\end{tabular}

methods can also be used for risk evaluation. It should be used a risk assessment method that best meets the workplace unique needs, without excluding the possibility of developing customized evaluation approaches, scoring methods and definitions of the parameters.

Another approach consists into quantifying the biological agent in air or surfaces to assess the exposure. However, exposures to biological agents are not measured frequently. There are some exposure measurement and sampling methods, but the absence of occupational exposure limits is a limitation for $\mathrm{OSH}$ practice. For biological agents that have toxic or allergenic effects, in the same way as for chemicals where it is possible to derive occupational exposure limits (OELs), there is lack of scientific evidence. For infectious biological agents, the deriving an OEL is more difficult owing to a lack of knowledge about exposure and pathogenicity. It is therefore not very likely that OELs for biological agents that result in infectious diseases will be developed soon [11]. However, the most important is the type of microorganisms (because that is what will define the measures to be implemented) rather than their concentration.

\subsection{Adapting the work process and defining the appropriate control measures}

In this phase usually the hierarchy of controls is applied (elimination, substitution, engineering controls, administrative controls, and personal protective equipment) [12]. The steps needed to remove or reduce the risks to workers will depend upon the particular biohazard, but there are a number of com-

Table 3

Risk Assessment Matrix

\begin{tabular}{|c|c|c|c|c|c|c|}
\hline \multicolumn{2}{|c|}{ Risk assessment matrix } & \multicolumn{5}{|c|}{ Injury severity } \\
\cline { 3 - 7 } & Insignificant & Minor & Moderate & Major & Critical \\
\hline \multirow{3}{*}{} & Highly likely & Medium & High & High & Extreme & Extreme \\
\cline { 2 - 7 } & Likely & Low & Medium & High & Extreme & Extreme \\
\cline { 2 - 7 } & Possible & Low & Low & Medium & High & High \\
\cline { 2 - 7 } & Unlikely & Rare & Rare & Low & Medium & Medium \\
\cline { 2 - 7 } & Rare & Rare & Rare & Low & Low & \multirow{2}{*}{ How } \\
\cline { 2 - 7 } & & & & & & \\
\hline
\end{tabular}

Table 4

Additional control measures, based on the assessed risk level for each biohazard

\begin{tabular}{|c|c|c|}
\hline Assessed risk level & Description of risk level & Actions \\
\hline Rare & $\begin{array}{c}\text { If an incident were to occur, there would be } \\
\text { rare that an injury would result }\end{array}$ & $\begin{array}{c}\text { Acceptable/tolerable risk No further actions are } \\
\text { needed }\end{array}$ \\
\hline Low & $\begin{array}{c}\text { If an incident were to occur, there would be } \\
\text { little likelihood that an injury would result }\end{array}$ & $\begin{array}{c}\text { Undertake the activity with the existing controls in } \\
\text { place }\end{array}$ \\
\hline Medium & $\begin{array}{c}\text { If an incident were to occur, there would be } \\
\text { some chance that an injury requiring First } \\
\text { Aid would result }\end{array}$ & Additional controls are advised \\
\hline High & $\begin{array}{c}\text { If an incident were to occur, it would be } \\
\text { likely that an injury requiring medical } \\
\text { treatment would result }\end{array}$ & $\begin{array}{c}\text { Controls will need to be in place before activity is } \\
\text { undertaken }\end{array}$ \\
\hline Extreme & $\begin{array}{c}\text { If an incident were to occur, it would be } \\
\text { likely that a permanent, debilitating injury or } \\
\text { death would result }\end{array}$ & $\begin{array}{c}\text { Consignificant control measures will need to be } \\
\text { implemented to ensure safety }\end{array}$ \\
\hline
\end{tabular}


mon actions that can be applied such avoiding the formation of aerosols and dusts or include decontamination measures for waste, equipment and clothing and appropriate hygienic measures for workers.

For the SARS-CoV-2 case, currently it is not possible to eliminate the risk, so the only and challenging option for a wide range of activities is to adapt workplaces and work processes and practices (collective and individual control measures) to minimise contamination. Community or public health measures should be implemented or adapted to the workplace reality, namely: social distancing ( 2 meters), hand hygiene, respiratory etiquette, disinfection of surfaces, self-monitoring of symptoms and individual protection. If personal contact is unavoidable, it must be reduced to the minimum. Obviously, employers must provide all the conditions needed to comply with those measures, such as hand sanitisers, adequate PPE or awareness campaigns (posters or flyers with basic hygiene rules to follow) [13]. Specific measures should be designed according the nature of the work/activity, and more information can be found in official sources of information on COVID-19 including WHO, European Centre for Disease Prevention and Control, European Commission, EU-OSHA, and national agencies/authorities for working conditions. In the case of laboratories manipulating biological agents, confinement measures should be considered, as presented in Table 5 .

As mentioned before, SARS-CoV-2 was classified in risk group 3, so Biosafety Level 3 (BSL-3) is required for laboratories handling and testing clinical specimens that might contain the virus. BSL-3 laboratories are almost always purpose-constructed containment laboratories, outfitted with specialized equipment and ventilation systems designed to ensure no airborne particles can exit the contained space. Site and activity-specific biosafety risk assessments

Table 5

Summary of biosafety levels as respective requirementes (adapted from [5])

\begin{tabular}{|c|c|c|c|c|}
\hline Biosafety level & 1 & 2 & 3 & 4 \\
\hline Description & No containment & Containment & High containment & Max containment \\
\hline $\begin{array}{l}\text { (containment; } \\
\text { health effects) }\end{array}$ & $\begin{array}{l}\text { Unlikely to } \\
\text { cause disease }\end{array}$ & $\begin{array}{l}\text { Disease of } \\
\text { varying severity }\end{array}$ & $\begin{array}{l}\text { Severe/potential } \\
\text { lethal disease }\end{array}$ & $\begin{array}{l}\text { Life-threatening } \\
\text { disease }\end{array}$ \\
\hline Pathogen type & $\begin{array}{l}\text { Agents that present } \\
\text { minimal potential } \\
\text { hazard to workers } \\
\text { and the } \\
\text { environment }\end{array}$ & $\begin{array}{l}\text { Agents associated } \\
\text { with human } \\
\text { disease and pose } \\
\text { moderate hazards } \\
\text { to workers and the } \\
\text { environment }\end{array}$ & $\begin{array}{l}\text { Indigenous or exotic } \\
\text { agents that } \\
\text { present a potential } \\
\text { for aerosol } \\
\text { transmission, } \\
\text { causing serious } \\
\text { disease }\end{array}$ & $\begin{array}{l}\text { Dangerous and } \\
\text { exotic agents that } \\
\text { pose a high risk of } \\
\text { aerosol } \\
\text { transmitted } \\
\text { laboratory } \\
\text { infections and } \\
\text { life-threatening } \\
\text { disease }\end{array}$ \\
\hline $\begin{array}{l}\text { Isolation of } \\
\text { laboratory Room } \\
\text { sealable for } \\
\text { decontamination }\end{array}$ & No & No & Yes & Yes \\
\hline Ventilation & No & Desirable & Yes & Yes \\
\hline Double door entry & No & No & Yes & Yes \\
\hline $\begin{array}{l}\text { Airlock/Airlock } \\
\text { with shower }\end{array}$ & No & No & Yes & Yes \\
\hline $\begin{array}{l}\text { Anteroom with } \\
\text { shower }\end{array}$ & No & No & $\begin{array}{l}\text { Yes (depending on } \\
\text { the agent used) }\end{array}$ & No \\
\hline $\begin{array}{l}\text { Wastewater } \\
\text { treatment }\end{array}$ & No & No & $\begin{array}{l}\text { Yes (depending on } \\
\text { the agent used) }\end{array}$ & Yes \\
\hline Autoclave & No & $\begin{array}{l}\text { No (but desirable } \\
\text { on-site) }\end{array}$ & Yes & Yes \\
\hline $\begin{array}{l}\text { Biological safety } \\
\text { cabinets }\end{array}$ & No & Desirable & Yes & Yes \\
\hline $\begin{array}{l}\text { Personnel safety } \\
\text { monitoring } \\
\text { capability (e.g. } \\
\text { closed-circuit } \\
\text { television, } \\
\text { two-way } \\
\text { communication, } \\
\text { etc.) }\end{array}$ & No & No & Desirable & Yes \\
\hline
\end{tabular}


should be performed to determine if additional biosafety precautions are warranted based on situational needs $[5,14]$.

\subsection{Recording findings and reviewing}

It is important that risk assessments are regularly reviewed and revised where necessary (whenever there are significant changes in materials, equipment, work methods, location or people involved, if there are accidents or complaints associated with the work and if natural disasters/catastrophes or epidemics occur). One of the main activities of the OSH services is to update the risk assessment, including the biological risk assessment and to thoroughly assess the critical points in each activity.

\section{Case I - Wastewater treatment plants}

\subsection{Characterization}

Using as example wastewater treatment plants (WWTP), the introduction of the SARS-CoV-2 hazard demands for an update to the risk assessment, although this activity already deals with the presence of microorganisms. The hazard brought up by the presence of SARS-CoV-2 in this type of setting will have its major implications in tasks/activities where there was no obligation for masks and other PPEs, confined spaces, places/tasks where employees come together, considering that before the pandemic outbreak the risk assessment already accounted for the need to protect the workers directly involved in the treatment process from the infection risk raised by the presence of microorganisms in wastewaters and their potential aerosolization during the treatment process.

A WWTP works on the removal of contaminants from wastewater or sewage and producing both a liquid effluent suitable for disposal to the natural environment and a sludge. To be effective, wastewaters and sewage are treated following various stages that are generally the same in all WWTP and involves the following processes: mechanical treatments (Influx, removal of large objects, removal of sand, preprecipitation), biological treatments (oxidation bed or aerated systems, post precipitation, effluent), and chemical treatments (this step is usually combined with settling and other processes to remove solids, such as filtration).

The technical classification of a WWTP is based on the steps performed during the treatment process: a) Primary treatment: mechanical processes to reduce oils, grease, fats, sand, grit, and coarse solids; b) Secondary treatment: is designed to degrade the solved content of the sewage within a biological degradation system, such as activated sludge systems that use the ability of microorganisms to decompose solved components in water. The final step at this stage is to separate the used biological component from the cleared sewage water; c) Tertiary treatment is more recent and still not present in many WWTP. This final stage aims to improve the effluent's quality to the standard required before it is discharged to the receiving environment and goes from nitrogen and phosphate elimination to disinfection processes. Figure 2 shows a usual WWTP circuit.

Besides the industrial treatment process, wastewater treatment plants harbour administrative offices, laboratories, and quality management offices. In the same workplace there will be different kinds of professionals, each of them facing different hazards, depending to their activities - process operators, maintenance operators, laboratory technicians, quality control operators, and administrative staff.

Updating the risk assessment due to the risk of SARS-CoV-2 infection will have more implications in the non-industrial areas, where the need for infectious risk protection was not previously present otherwise than in the industrial treatment process. The hazards shall be identified considering the number of workers in each work site, the use of common areas, the treatment of work clothes, sites where aerosolization occurs and their ventilation circuits.

\subsection{Risk assessment for inhalation of infectious agent (SARS-CoV-2)}

Hazards such sharing office supplies and equipment, inappropriate use of PPE, non-compliance with social distancing or possible exposure to contaminated water could lead to the risk of inhalation of the infectious agent. In fact, a technical brief from WHO suggested that there is no evidence about the survival of SARS-CoV-2 in wastewater [15]. However, significant knowledge gaps exist on the potential role of wastewater in the transmission of SARS-CoV-2. Survival of SARS-CoV-2 in environmental media remains mostly unknown [16], but recent data revealed the presence of SARS-CoV-2 in wastewater [17]. So, in WWTP context, OSH practitioners should consider the application of prevention 


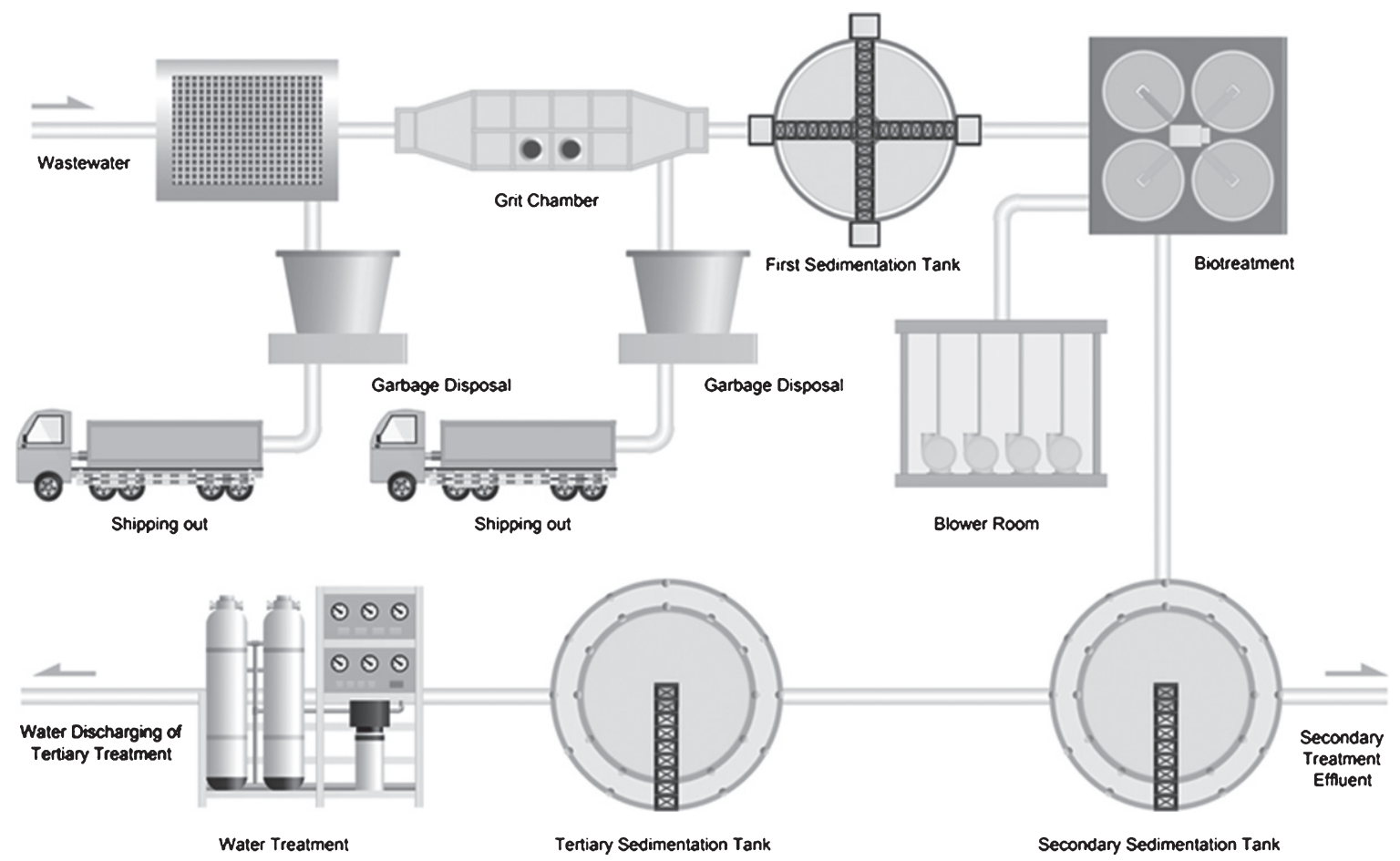

Fig. 2. Conventional wastewater plant circuit (scheme from Edraw Max, Edrawsoftã).

measures to minimize workers exposure, until research outcomes clarify this possible contamination route. In this example, the results reflect the reality of this specific WWTP. The work is mostly done outdoors, and previous measures were already implemented in the laboratory since the workers were exposed to other biological agents. Table 6 exemplifies the result of the application of the risk assessment method described in this article.

\section{Case II - Orchestra}

\subsection{Characterization}

Orchestras illustrate a challenging setting when thinking on SARS-CoV-2 prevention measures. Usually, an Orchestra may have up to 80 members in the different instrument sections and depends on their simultaneous performance. Additionally, PPE is not always possible since many instruments require the use of the mouth.

A typical classic orchestra comprehends 4 instrument families - percussion, woodwinds, brasses, and strings - and a conductor, and might add a piano player and a singer (Fig. 3).

\subsection{Risk assessment for inhalation of infectious agent (SARS-CoV-2)}

Even without studies fully assessing the dispersion ability of particles originating from playing woodwind and brass instruments, it is still clear that the risk of generating droplets is high as playing these instruments involves deep breathing and forced exhalation, creating a strong airflow around the player [19, 20]. The risk assessment is critical for this activity. In face of the still unknow dynamics for SARS-CoV-2 spreading combined with the unknown behaviour of the airflows generated by playing the instruments, the need to account for these hazards is new for musicians (Orchestras') occupational risk assessment. The risk assessment matrix shall consider the risk for contamination by inhalation, and the possibility of creating a safe distance between orchestra members. Table 7 shows an example of a risk assessment in Orchestras'.

\section{Conclusion}

The occupational risk assessment is a legal obligation of employers and is mostly conducted by OSH practitioners, who are facing a new challenge 
Table 6

WWTP biological risk assessment

\begin{tabular}{|c|c|c|c|c|c|}
\hline Area/Location & Tasks & $\begin{array}{c}\text { Hazard } \\
\text { likelihood }\end{array}$ & $\begin{array}{c}\text { Injury } \\
\text { s everity }\end{array}$ & Risk level & Actions \\
\hline Administration & $\begin{array}{l}\text { Administrative/office } \\
\text { work }\end{array}$ & Rare & Moderate & Low & \multirow{8}{*}{$\begin{array}{l}\text { Undertake the } \\
\text { activity under } \\
\text { the existing } \\
\text { controls in } \\
\text { place }\end{array}$} \\
\hline Pre -treatment & $\begin{array}{c}\text { Operation and } \\
\text { management }\end{array}$ & Unlikely & Moderate & Low & \\
\hline Primary t reatment & $\begin{array}{l}\text { Operation and } \\
\text { management }\end{array}$ & Unlikely & Moderate & Low & \\
\hline $\begin{array}{r}\text { Secondary } \\
\text { treatment }\end{array}$ & $\begin{array}{c}\text { Operation and } \\
\text { management }\end{array}$ & Unlikely & Moderate & Low & \\
\hline Filtration & $\begin{array}{c}\text { Operation and } \\
\text { management }\end{array}$ & Unlikely & Moderate & Low & \\
\hline Disinfection & $\begin{array}{l}\text { Operation and } \\
\text { management }\end{array}$ & Unlikely & Moderate & Low & \\
\hline $\begin{array}{c}\text { Sludge } \\
\text { processing }\end{array}$ & $\begin{array}{l}\text { Operation and } \\
\text { management }\end{array}$ & Unlikely & Moderate & Low & \\
\hline $\begin{array}{c}\text { Biosolids } \\
\text { processing }\end{array}$ & $\begin{array}{c}\text { Operation and } \\
\text { management }\end{array}$ & Unlikely & Moderate & Low & \\
\hline \multirow[b]{2}{*}{ Laboratory } & Wastewater sampling & Possible & Moderate & Medium & \multirow{4}{*}{$\begin{array}{l}\text { Additional } \\
\text { controls } \\
\text { advised }\end{array}$} \\
\hline & $\begin{array}{l}\text { Wastewater analyses } \\
\text { (microbiological, } \\
\text { physical, and } \\
\text { biological parameters) }\end{array}$ & Possible & Moderate & Medium & \\
\hline $\begin{array}{c}\text { Lift stations } \\
\text { (confined spaces) }\end{array}$ & $\begin{array}{c}\text { Operation and } \\
\text { management }\end{array}$ & Possible & Moderate & Medium & \\
\hline $\begin{array}{l}\text { Personnel } \\
\text { common areas: } \\
\text { canteen, locker } \\
\text { room, restrooms }\end{array}$ & --- & Possible & Moderate & Medium & \\
\hline
\end{tabular}

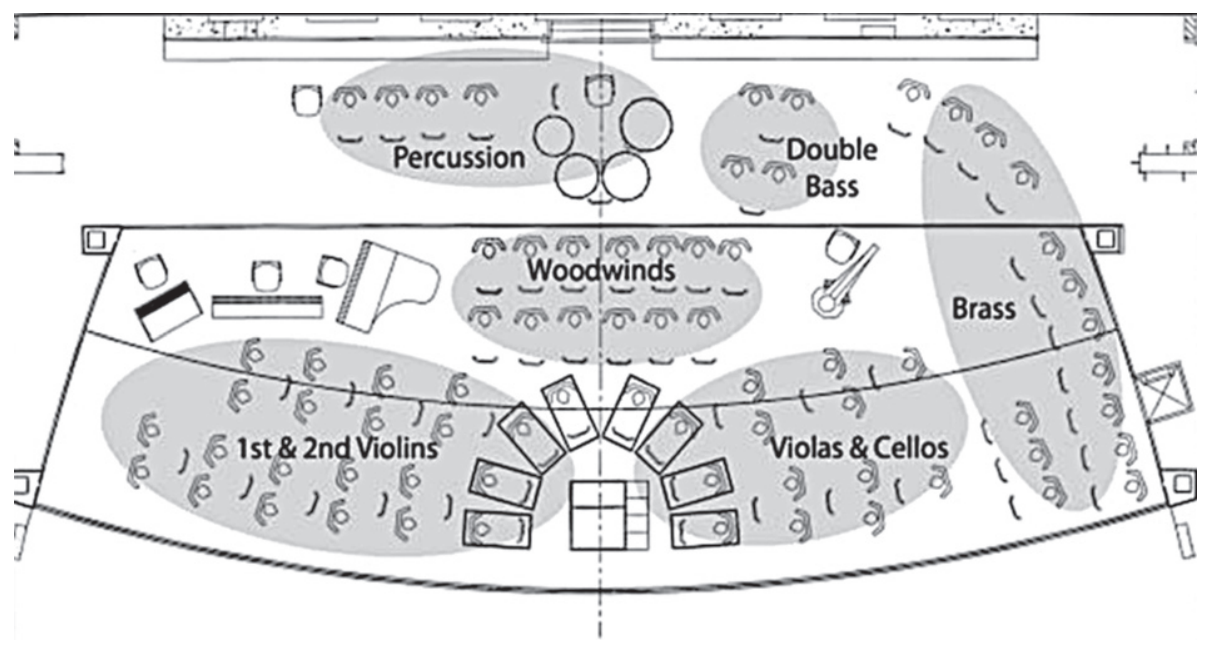

Fig. 3. Conventional layout for an orchestra. (Reprinted from the International Journal of Industrial Ergonomics, Vol 43(6), "Noise exposure and hearing loss in classical orchestra musicians" by F. Russo, A. Behar, M. Chasin, S. Mosher. Copyright (2013) with permission from Elsevier [18]). 
Table 7

Orchestra biological risk assessment

\begin{tabular}{|c|c|c|c|c|}
\hline Task & $\begin{array}{c}\text { Hazard } \\
\text { likelihood }\end{array}$ & $\begin{array}{c}\text { Injury } \\
\text { s everity }\end{array}$ & $\begin{array}{c}\begin{array}{c}\text { Assessed risk } \\
\text { level }\end{array} \\
\end{array}$ & Actions \\
\hline Conductor & Possible & Moderate & Medium & \multirow{6}{*}{$\begin{array}{l}\text { Additional controls } \\
\text { advised }\end{array}$} \\
\hline Woodwind & Possible & Moderate & Medium & \\
\hline Brasses & Possible & Moderate & Medium & \\
\hline Percussion & Possible & Moderate & Medium & \\
\hline Strings & Possible & Moderate & Medium & \\
\hline Singer & Possible & Moderate & Medium & \\
\hline Piano & Unlikely & Moderate & Low & \multirow{3}{*}{$\begin{array}{l}\text { Undertake the activity } \\
\text { under the existing } \\
\text { controls in place }\end{array}$} \\
\hline Sound technicians & Unlikely & Moderate & Low & \\
\hline Light technicians & Unlikely & Moderate & Low & \\
\hline
\end{tabular}

within the pandemic context. Employers from activities where the use of biological agents is deliberate, must be aware that in some countries (for instance, EU members) prior notification shall be made to the competent authority (on working conditions issues) of the use for the first time of: group 2 biological agents; group 3 biological agents; group 4 biological agents. Laboratories testing SARS-CoV-2 are an example of such obligation. However, currently, workers from all activity sectors are exposed to a biological agent (SARS-CoV-2) and the biological risk should be considered and assessed in all types of activity. Following OSH prevention principles, OSH practitioners must be aware of emerging risks and prepared to deal with the novelty of those risks. Also, the link between scientific outcomes addressing the occupational exposure to SARS-CoV-2, to the technical practice, plays a very important role. In this sense, a biological risk assessment method was presented and applied to two different activities: one where biological agents were already considered during risk assessment (WWTP), and other where no biological hazards were previously identified (Orchestra). Both examples considered the risk of 'inhalation' the infectious agent. A similar approach must be followed to cover each possible route of transmission within the activity in analysis. The results obtained for both cases, revealed low or medium risk level of inhalation of SARS-Cov-2, for the assessed tasks. The injury severity was considered "moderate" for both cases. The risk must be assessed based on the specific real conditions, considering all the measures already in place and possible adjustments, which means that in some situations, the injury severity could be classified as "major". However, in both cases, the assessment considered that vulnerable workers were working from home or in medical leave. For medium risk level, additional controls are advised, such maintain social distancing, sanitize instruments/equipment before use, use proper and well-maintained PPE (when applicable), and promote awareness sessions to spread good practices at work.

\section{Acknowledgments}

The authors acknowledge the funding provided by Fundação para a Ciência e a Tecnologia (FCT) through the scholarship SFRH/ BD/130203/2017.

\section{Conflict of interest}

The authors declare no potential conflicts of interest with respect to the research, authorship, and/or publication of this article.

\section{References}

[1] World Health Organization (WHO). Novel Coronavirus (2019-nCoV) Situation Report - 1. WHO Bull. 2020;:1-7. 
[2] World Health Organization (WHO). Coronavirus disease 2019 Situation Report 51 11th March 2020. World Heal Organ [Internet]. 2020;2019:2633. Available from: https:// www.who.int/emergencies/diseases/novel-coronavirus2019

[3] International Labour Organization. A 5 STEP GUIDE for employers, workers and their representatives on conducting workplace risk assessments International Labour Off ce Geneva. 2014; Available from: www.ilo.org/publns

[4] Rim KT, Lim CH. Biologically hazardous agents at work and efforts to protect workers' health: A review of recent reports. Saf Health Work. 2014;5(2):43-52.

[5] World Health Organization (WHO). Laboratory biosafety manual. $3^{\text {rd }}$ ed. Geneva: World Health Organization, 2004, p. 178.

[6] European Parliament. Diretive 2000/54/CE, from 18 of September of 2000. Off J Eur Communities. 2000;4:L 262/21-44.

[7] Health and Safety Authority (UK). Risk Group Classification for Severe Acute Respiratory Syndrome Coronavirus 2. 2020;2:2-3

[8] European Comission. Directive 2020/739 Amending Annex III to Directive 2000/54/EC of the European Parliament and of the Council as regards the inclusion of SARS-CoV-2 in the list of biological agents known to infect humans and amending Commission Directive (EU) 2019/1833, from 3 of June of 2020. 2020:11-4.

[9] World Health Organization (WHO). COVID-19: vulnerable and high risk groups [Internet]. 2020. Available from: https://www.who.int/westernpacific/emergencies/covid19/information/high-risk-groups

[10] European Agency for Safety and Health at Work (EUOSHA). OiRA Tools [Internet]. 2020. Available from: https://oiraproject.eu/en/oira-tools
[11] European Agency for Safety and Health at Work (EUOSHA). Biological agents and work-related diseases : results of a literature review, expert survey and analysis of monitoring systems. 2019. 1-347.

[12] Centers for Disease and Control (CDC). Hierarquy of Controls [Internet]. 2015. Available from: https://www.cdc.gov/ niosh/topics/hierarchy/default.html

[13] Cockburn W. Covid-19 : Back To the Workplace. Eur Agency Saf Heal Work. 2020;1-16.

[14] Iwen PC, Stiles KL, Pentella MA. Safety Considerations in the Laboratory Testing of Specimens Suspected or Known to Contain the Severe Acute Respiratory Syndrome Coronavirus 2 (SARS-CoV-2). Am J Clin Pathol. 2020;153(5):567-70.

[15] World Health Organization (WHO). Water, sanitation, hygiene and waste management for the COVID-19 virus. Vol. 1, World Health Organization. 2020.

[16] Kitajima M, Ahmed W, Bibby K, Carducci A, Gerba CP, Hamilton KA, et al. SARS-CoV-2 in wastewater: State of the knowledge and research needs. Sci Total Environ. 2020;739:139076.

[17] La Rosa G, Iaconelli M, Mancini P, Bonanno Ferraro G, Veneri C, Bonadonna L, et al. First detection of SARSCoV-2 in untreated wastewaters in Italy. Sci Total Environ. 2020;736:139652.

[18] Russo F, Behar A, Chasin, M, Mosher, S. Noise exposure and hearing loss in classical orchestra musicians. Int J Ind Engon. 2013;43:474-8.

[19] Richard M, Kok A, de Meulder D, et al. SARS-CoV-2 is transmitted via contact and via the air between ferrets. Nat Commun. 2020;11:1-6.

[20] Zhang R, Li Y, Zhang AL, Wang Y, Molina MJ. Identifying airborne transmission as the dominant route for the spread of COVID-19. Proc Natl Acad Sci USA. 2020;117:14857-63. 